\title{
Food counterfeiting in general; counterfeiting of milk and dairy products
}

\author{
János Csapó ${ }^{1,2}$ - Sándor Némethy ${ }^{3,4}$ - Csilla Albert ${ }^{2}$ \\ ${ }^{1}$ University of Debrecen, Institute of Food Technology, Hungary; ${ }^{2}$ SAPIENTIA Hungarian University of Transylvania, \\ Department of Food Science, Romania; ${ }^{3}$ University of Gothenburg, Department of Conservation, Sweden; ${ }^{4}$ University of Pécs, \\ Institute of Regional Development, Hungary
}

e-mail addresses: csapo.janos@agr.unideb.hu,csapo.janos@gmail.hu; sandor@conservation.gu.se; albertcsilla@.cs.sapientia.ro

\begin{abstract}
After giving a general description and historic perspective of food counterfeiting, the questions regarding food counterfeiting today, the nature of food counterfeiting, detection and combating food counterfeiting, and possible legal sanctions against food counterfeiting will be answered. Then the establishment and role of national anti-counterfeit organizations, the national anti-counterfeiting strategy, the expected benefits of actions against counterfeiting, the punishment of counterfeiting, and some cases regarding the counterfeiting of food are discussed.

In the case of counterfeiting of milk and dairy products, the milk of various animal species, buffalo, goat, and sheep, as well as cows' milk is being falsified by mixing soymilk with cow's milk. Hereinafter, the detection of whey and the buttermilk from milk, the determination of whey protein from dairy products, the analysis of milk produced from milk powder and other options for milk and milk product counterfeiting are discussed. Finally, questions regarding the detection of other fats in milk, butter, and ghee, the dilution of milk, determination of the heat treatment of milk and dairy products, the detection of the amount of spoiled milk unfit for consumption are answered. Analytical methods that can be used to detect counterfeits are always referred to.
\end{abstract}

Keywords - food counterfeiting, milk, whey, dairy products, heat treatment, anti-counterfeit organizations, forgery

\section{Introduction}

Since humankind has begun to produce food, food counterfeiting has come along with food production. The earliest written records of food counterfeiting can be traced back to ancient times when the laws of Hammurabi prohibited the sale of poor quality or excessively expensive beers, and those who breached these laws could face even capital punishment (King \& Brians, 2015). There are written memoirs about the falsification of the wine in the Roman Empire, mostly dilution with water, which was also severely punished (Roman Agriculture). Nowadays, crook manufacturers and traders falsify almost everything, but in parallel with counterfeiting, procedures that are suitable for detecting counterfeit food have been developed, providing information about the nature of counterfeiting (Csapó et al., 2016). For example, milk has been counterfeited in recent times, as its dilution with water is easy to achieve due to cheap and easy access to water. In England, before the 1800s, the falsification of milk with tap water was a daily practice, that could be unveiled only when methods were developed at the end of the century to detect milk counterfeiting (Albert \& Csapó, 2016; Monteiro et al., 2013). Milk counterfeiting still exists, because in certain countries and regions it is a daily practice to mask the dilution with addition of salt, occasionally adding cooking oil and detergents to the milk to increase the fat content of the milk (Csapó et al., 2016). 
There is also a significant amount of counterfeited milkbased, extremely expensive cheeses. The first counterfeiting in the United States occurred in the 1870s when the falsification of high-quality Wisconsin cheeses was discovered with cheap fats, such as lard, to increase their weight. Since the fact of counterfeiting had been discovered, the export of such cheeses had fallen, they had lost their reputation, which took decades to recover (Csapó et al., 2016). The fact of counterfeiting has not ceased even today, as the very expensive cheeses are still being imitated, even though the quality of these cheeses is not even close to the high-quality, expensive cheeses sometimes matured for years.

\section{Are foods being counterfeited today?}

The answer is undoubtedly yes, because news about the counterfeiting of food in the media come up regularly, let's just think about the recent scandals when honey has been falsified with high fructose corn starch hydrolysate until a method has been developed to detect such foreign matter from honey (Herpai et al., 2013). Two counterfeit scandals have recently emerged in relation to wines. In Austria, antifreeze containing ethylene glycol was used to produce wines with greater body, which caused severe intoxication. The consequence was that Austrian wines disappeared from the shelves of European supermarkets (Kirsch, 2016).

Unfortunately, the same scandal was repeated in Hungary when trying to improve the Bull's Blood of Eger with glycerol, which is not toxic to the human body and constitutes a natural component of the wine, but its presence is a counterfeit beyond a certain tolerance limit (Weekly World Economics, 2009). It is very easy to falsify various beverage items that are usually made from concentrates diluted with a sufficient amount of water. Since the price of concentrates is primarily determined by the sugar content, they are often counterfeited by the addition of different sugars. For example, in the orange juice, the ratio of glucose, sucrose, and fructose is $1: 2: 1$, so this food is forged with invert sugar extracted from sugar beet, in which the proportion of sugars is the same as in orange juice. In addition to sugar, various organic acids are added to foods to maintain the right acid-sugar ratio (Moore et al., 2012). Of course, in parallel with counterfeiting, a number of methods have been developed that can demonstrate the bare existence of counterfeiting. In this case, it has been discovered that invert sugar also contained trisaccharide, one of the indicators of counterfeiting. As a result of industrial production, the malic acid used to adjust the acid ratio is available in DL, while orange juice contains only the natural L-variant. In synthetic compositions, the ratio of $D: L$ is $1: 1$, so if such artificial apple juice is mixed with orange juice, the presence of D-malic acid will indicate counterfeiting. The D stereo-isomeric malic acid can be easily detected nowadays both enzymatic method and by highperformance liquid chromatography (HPLC; Hammond, 2012).

Many more similar counterfeiting procedures could be described, but this is not possible in this brief summary. However, it can be seen from the above that almost every food in the world can be counterfeited, and there may be some rude cases where the materials used for counterfeiting are extremely dangerous to the human body and can even be fatal. Examples of this were the falsification of the Hungarian ground paprika mixed with lead oxide (Kasza, 2009; Csóka, 2014) to make its colour more desirable, or the falsification of infant food in China with melamine, which increased its crude protein content and caused the death of several infants (Associated Press, 2008).

\section{Food counterfeiting and its legal background}

What is food counterfeiting? Counterfeit food is - which is not produced in accordance with the specifications or described in the declarations in the product sheet, - which have not been authorized or produced according to registered methods or have been placed on the market,

- which have been produced using unauthorized ingredients which has been re-labeled or repacked in an unlawful manner, - which have been subject to unauthorized extension of their shelf-life, or have been produced in whole or in part from materials with expired quality preservation time or shelf-life, - which have not been produced for human consumption or have been placed on the market for human consumption but unfit for human consumption.

Food counterfeiting may perhaps be better understood from the following examples. Fake is the food that:

- has been made from expired ingredients,

- a cheap product has been marketed with the packaging and price of the more expensive product (for example, when soya oil treated with dye is sold as extra virgin olive oil or when cheap cooking oil is marketed as high-quality cooking oil),

- unauthorized ingredients are used (unauthorized dyes, preservatives, sweeteners),

- counterfeiting protected products (products marketed as Parmesan or Feta cheese but produced by other technologies, for example counterfeiting Parma ham with meat products from other places),

- non-organic products are placed on the market as organic products,

- dairy products containing vegetable fat (milk mixed with vegetable oil or margarine to produce high-fat cheeses),

- chocolate products containing vegetable fat; cocoa butter is replaced with vegetable fat,

- artificial honey is produced using sugar syrup, organic acids, vitamin $\mathrm{C}$ and various enzymes,

- the name of the product does not comply with the statutory provisions, or, in addition to the commonly known name of the product, the quality required by law and the consumer does not appear in the product (the four eggs pasta does not contain eggs; the product called salami does not meet the quality standards for such a product).

- selling imported products as domestic (domestic sales of seasonal fruits, strawberries, and cherries in March, April).

\section{How to combat food counterfeiting?}

Counterfeiting of food was a crime at all ages in all societies. In Hungary already in 1896, a law on food counterfeiting was 
provided. Today, food counterfeiting has become an international phenomenon, which, in addition to the economic damage it causes, poses a direct health and food safety risk to the consumer. In Hungary, the main body for combating illegal food counterfeiting is the Food Chain Monitoring Authority, which, in cooperation with various coauthorities, performs inspections on a regular basis, according to an official control plan, on the basis of consumer notifications, or in case of suspicion.

Food counterfeits are under the control of the aforementioned Authority for the whole area of food production and distribution, and attempts are made to prevent counterfeiting by ensuring traceability. The purpose of these investigations is, among other things, to identify the proceeds of illegal activities and to protect the interests of producers, distributors, and consumers who are engaged in legal activities. In Hungary, the legal background for these investigations is the "Law on Food Chain and Regulatory Supervision 2008" (public database on infringements in the food chain and Decree 3/2010 on the provision of data and traceability of food production and distribution).

\section{What regulatory measures can be taken to detect counterfeiting?}

It is possible to restrict or prohibit to place certain products on the market, restrict or prohibit their import or export; the product may be withdrawn from the market, the recalled product may be destroyed or disposed of; the provision of food production activities may be suspended, restricted or forbidden for a definite period of time; re-operation may be subject to strict conditions; the approval of installations may be suspended or revoked.

\section{What sanctions can be imposed in the case of food counterfeiting?}

Penalties may include food inspection fines, food chain supervision fines, procedural fines or infringement fines. In the case of food counterfeiting, no warning may be applied, the sanction must have strict moral and financial consequences. Criminal proceedings must be initiated in the following cases:

- Forgery of a unique identification label.

- Abuse of public consumption products harmful to health.

- Placing a poor-quality product on the market.

- Issue of a false quality certificate.

- Misleading labeling the food, deliberately deceiving consumers.

\section{In recent years, the following cases of food counterfeiting} have been identified in Hungary:

- Milk powder has been found to contain vegetable fat.

- Sugar added to honey.

- Sugar sweetener has been added to icing sugar, the quality preservation period is poorly stated.

- Meat products made from poultry meat were falsely labeled. - Bakery products were manufactured in an unlawful way.
- Mineral water was produced using unregistered methods.

- Raw milk and smoked finished products were produced without permission.

- After slaughtering in an unauthorized place, foodstuffs have been illegally placed on the market for public consumption.

\section{National anti-counterfeit organizations}

The creation of the National Anti-Counterfeit Board and the development of a national anti-counterfeit strategy were of paramount importance in the fight against food counterfeiting. The strategy identifies the necessary measures for the food industry as follows:

- review of legislation in the field of food counterfeiting on the basis of practical experience of the legislative authorities; - developing tools for detecting counterfeits;

- building up an up-to-date, publicly accessible database of food counterfeit data;

- initiate a communication campaign focusing on consumer protection aspects of food counterfeiting, developing a legal aid service, and training and educating public authorities.

The strategy is implemented through the action plan. The Board annually monitors the implementation of the strategy, discusses changes in the domestic situation of food counterfeiting. The Food Anti-Counterfeiting Action Plan contains the following main points:

- review and, if necessary, amend legal provisions to ensure the effectiveness of the official anti-counterfeiting intervention;

- monitoring the case-law on the verification of the use of geographical indications;

- promoting cooperation and exchange of experience between the competent authorities responsible for combating food counterfeiting, other relevant professional organizations, and organizing professional events and consultations;

- public education through public media and other forms of information and through school education;

- defining the concept of food counterfeiting and establishing a system of sanctioning it;

- developing tools for laboratory testing.

\section{What are the benefits of taking actions against food counterfeiting?}

More effective actions against placing on the market counterfeit foods or food products labeled with false information, appearing as protected high-quality brands, will help to promote original and protected products of good quality. Cleaning the market, exerting a deterrent effect on the perpetrators, bleaching the black economy and protecting consumers from fake and dangerous products, will ultimately improve food security.

\section{Some examples of food counterfeiting}

The most common counterfeit foods include olive oil, milk, honey, saffron, orange juice, coffee, and apple juice. These foods are counterfeited, i.e., the components contained therein are deliberately replaced, replaced, or lost from the 
ingredients without being brought to the attention of the customers. The cause of counterfeiting is always material gain. Fake components are often unknown, so they are often difficult to discover.

Until 2007, melamine was not considered as a pollutant or a substance used for counterfeiting before being detected in dog feeds or before being mixed into infant formulas and other dairy products in 2008. Later it turned out that melamine has been used for counterfeiting since 1979 to achieve higher protein content, which remained hidden until 2007. There was no suspicion of counterfeiting with melamine because the testing of melamine was not part of routine quality control. It is impossible to plan a full anticounterfeit food system to detect a virtually infinite number of possible counterfeiting components because the analytical capacity of the world would not be enough. A number of additives present a high risk because they are used in many foods, they have no particularly distinctive properties, and have no qualities that can be easily distinguished from other ingredients.

For example, glycerol, which has recently been used to "refine" some of the red wines in Hungary, is a sweet, colourless liquid that is difficult to distinguish from other sweet, colourless liquids such as toxic diethylene glycol, previously added to red wine as a substitute for glycerol, which had a lethal effect. It is also very difficult to detect fraud, because in $95 \%$ of fraud cases, counterfeit material is replaced by a less expensive, similar component that can only be discovered if they know what they are looking for. An example of such substitution fraud is the partial replacement of olive oil with peanut oil or the partial replacement of lowquality ground red paprika with poisonous lead tetroxide or lead chromate.

Because of this, it is more appropriate for a food to look at what it should contain and what quantity, and not what it should not contain. Protection against food counterfeits can be efficient by constantly monitoring components that must be included in guaranteed, high-quality food. A well-designed analysis can detect both the known and the unknown counterfeit components, which is a great advantage in an environment where you cannot know what dangerous counterfeit we might encounter in the future.

An illustrative case to assess the extent and the damages of food counterfeiting is the joint action of Interpol and Europol carried out in the first week of December 2012, with the help of the authorities in 29 countries. As a result of the investigations, 135 tons of potentially dangerous, and another 100 tons of misleading and potentially dangerous food products were seized. Counterfeits included coffee, cassava, olive oil, and caviar from luxury products. During the oneweek checks, 385,000 liters of fake liquids such as vodka, wine, soy sauce, and orange juice were found. In addition, fish, meat, sweets, and spices unfit for human consumption were discovered. As a result of the investigations, it was emphasized that counterfeit and doubtful foods and beverages are produced, transported, stored and marketed without complying with quality standards and hygiene requirements. The consumption of these products poses a serious health risk to consumers, but their production and distribution is a very profitable business for counterfeiters.

According to data from recent years, around $\$ 50$ billion of counterfeit food is sold worldwide, mostly milk powder, baby food, instant coffee, soft drinks, or alcoholic beverages. Alcoholic beverages are counterfeited in particularly large quantities in order to avoid high taxes and to generate higher revenues. Generally, counterfeit food accounts for about $10 \%$ of all counterfeit products sold around the world, but in parallel with rising food prices, this rate is likely to increase. The consumption of fake foods and beverages is a serious health risk that may be even lethal in some cases. For example, if infants are fed with diluted baby food, they will be malnourished and may even die if the food contains ingredients of non-controlled origin, which can contain dangerous toxic ingredients.

Counterfeiters are not interested in and sometimes unaware of the consequences of consuming their products, their sole aim is to maximize profit. Of course, not all food can be checked, because there is not enough food-analytical capacity. For example, in the United States, about 10 million food preparations are received each year, but only $1 \%$ of them are checked and only $0.3 \%$ are sampled. The amount of imported food is so huge that even such a rich country cannot control it, so they mainly focus on the higher risk factors. The authorities intend to develop a system that can be able to easily filter out the riskiest shipments.

Recently, counterfeiting of alcoholic beverages has stunned public opinion. In 2008, a fake vodka was marketed in England that had a very high content of methanol, which could cause permanent blindness. The label of the alcoholic beverage placed on the market imitated the original, highquality vodka, thus deceiving the consumer, but after the fake was opened, it was possible to feel an unpleasant, chemicallike smell, indicating that it was not all right. A similar type of poisoning has been reported in Russia, where a state of emergency was introduced in 2006 in the Siberian region due to mass poisoning by fake vodka. In 2008 , the consumption of counterfeit drink caused the deaths of more than 60 people in India and the frequent seizure of alcoholic beverages sold without a seal by the Hungarian authorities has previously revealed illegal distilleries. In 2007, nearly 2 million liters of spirits were produced from 600,000 liters of window washing liquids in Hungary. In 2008, the customs found 1,200 liters of unlicensed alcohol, which revealed the existence of several unlicensed distilleries and an illegally operated brandy distillation device exploded in a family house.

\section{Is counterfeiting punishable?}

Section IV of the Penal Code 1978 regulates the legal actions in connection with criminal offenses related to violations of intellectual property rights (counterfeiting). It states that counterfeiting is a criminal offense and that its perpetration may result in imprisonment. The new Criminal Code, which came into force on 01.07 .2013 , particularly strictly penalizes 
counterfeiting and other commercial infringements of intellectual property rights.

\section{Counterfeiting of milk and dairy products and detection of counterfeits}

Various materials, tools, processes, and technologies are used to falsify all kinds of food, while various analytical methods have been developed for detecting food counterfeiting, mostly large-scale techniques (Csapó et al., 2016). The description of these methods just for some of the most important basic foods would fill several volumes, so we would like to present the sophisticated methods of counterfeiting milk and dairy products and the occasionally sophisticated analytical methods that can be used to detect counterfeiting (Csapó et al., 2006, 2007, 2008).

Good quality milk and dairy products are free from dirt, antibiotics, unpleasant smells and flavors, pathogenic microorganisms, their somatic cell count and the total number of germs are low, no water added, no fat taken away, no other material mixed, the smell is pleasant and the milk has a characteristic taste and composition that corresponds to the composition of normal milk. In the case of milk, the bacteriologic conditions while for dairy products the flavor and aroma compounds should be particularly observed (Csapó \& Csapóné, 2002, 2009a, b).

It is counterfeit if you add anything, especially water, to milk, or anything else, especially fat, to get more profit (Csapó \& Salamon, 2006). Mostly, water or skimmed milk is added to the milk and a significant portion of the original fat content is removed, which can be checked by density measurement, freezing point control or fat content determination (Csapó, 2000, 2014; Csapó et al., 2016). Dirty water, detergents, plant cells, hair, household powder and dirt, animal urine and faeces are clearly visible, smelling and repellent in milk (Csapó \& Csapóné, 2002). Finding other unseen and nonsensical counterfeits improves the quality of commercial milk and dairy products, so knowing these methods is important for both buyers and quality control institutions. In several countries, a system of points has been introduced that penalizes the quality of the milk and gives the farmers who produce the inadequate milk a lower income. Particular attention is paid to the contamination of milk with antibiotics, radioactive substances, chlorinated hydrocarbons, and heavy metals (Csapó \& Csapóné, 2002; Csapó \& Salamon, 2006; Csapó \& Schaffer, 2001).

\section{Milk from different animal species and their counterfeiting}

The combination of cow's milk and buffalo milk, mixing of cow, goat and sheep's milk, for counterfeiting, occurs all over the world. In particular, goat milk is used as a preference for cow's milk falsification, although it is often the case that the otherwise high-quality goat milk is falsified with water or cow's milk in order to achieve greater profit (Bania et al., 2001; Darwish et al., 2009). If the goat milk is falsified with cow's milk, its nutritional value does not change, and even if the amount of added cow's milk does not exceed $15 \%$, its detection is also very difficult. This situation is particularly problematic in the production of cheese, because different types of milk give the cheese a different flavor and aroma, and even the milk of the alien species can cause an allergic reaction in the body of the consumer (Haza et al., 1999).

Several methods have been developed to uncover this type of counterfeiting (Lee et al., 2001). Immunological (Aranda et al., 1988; Bitri et al., 1993; Castro et al., 1992) and nonimmunological gel electrophoresis was used to separate the milk of the different species (Cartoni et al., 1999; Kaminarides \& Koukiassa, 2002; Lee et al., 2001; Muller et al., 2008), and in particular isoelectric focusing (Spoljaric et al., 2013; Mayer et al., 1997) could be applied to the proteins efficiently, while gas chromatography (IDF 2010; Guittirez et al., 2009; Cartoni et al., 1999) and HPLC (Ferreira \& Oliveira, 2003) can be used to the casein macropeptides and fatty acids. The chemical composition and UV spectrum are also different for such milk, which provides an opportunity for identification (Csapó \& Csapóné, 2002). The different fatty acid composition of cow's milk and goat's milk, as well as the differences between the fatty acid indexes also make identification possible (Cartoni et al., 1999; Detaillats et al., 2006, IDF 2010).

Particularly suitable for this purpose are short-chain fatty acids or indexes of their concentrations, and gas chromatographic analysis, also proved that goat and sheep cheeses can be characterized by other short-chain fatty acid patterns than cow's milk, and therefore the cheeses can be distinguished from each other (Gattuzo \& Fazion, 1980). The ratio of lauric acid to capric acid in cheese made from cow's milk is on average 1.16, while in goat cheese it is 0.46 and in sheep's cheese 0.58 . This ratio is suitable for providing information on the amount of cow's milk in goat and sheep cheeses. Mixing of cow's milk with goat's milk can also be detected on the basis of the $\beta$-carotene content, as this compound is not found in goat milk. Mixing $20 \%$ goat milk with cow's milk can also be detected by the UV spectrum (Iverson \& Sheppard, 1989).

Enzymatic methods have also been developed to detect cow's milk mixed with sheep's milk, based on the significantly higher riboflavin content of cow's milk and the activity of xanthine oxidase, according to which $2 \%$ cow's milk can be detected by this method. The limitation of the method is that heat treatment destroys the enzyme activity and it cannot be applied to heat-treated milk.

The mineral content of sheep, goat and cow's milk is relatively constant, but the proportions of the different elements in the different kinds of milk are very variable. The amount of minerals is influenced by the technology used, for example, when different cheeses are made from milk, but there are distinct differences between cheeses made from different kinds of milk (Fresno, 1995). The ratio of calcium to magnesium is e.g. 23.3 in cow's milk and 17.2 in sheep's milk, which makes it possible to distinguish between the two dairy products. Differences were found between the three 
species, regarding the $\mathrm{K} / \mathrm{Mg}, \mathrm{Na} / \mathrm{Ca}, \mathrm{Cu} / \mathrm{Zn}$, and $\mathrm{Cu} / \mathrm{Na}$ ratios and by multi-variance analysis of trace elements $(\mathrm{Cr}, \mathrm{Mn}, \mathrm{Fe}$, $\mathrm{Ni}, \mathrm{Cu}, \mathrm{Zn}, \mathrm{Mo}, \mathrm{Cd}$, and $\mathrm{Pb}$ ) the separation milk of different species was possible (Favretto et al., 1992).

Cheeses made from milk of different species could be separated, for example by electrophoresis, based on the different motility of the different casein fractions (especially $\kappa$-casein), and whey protein fractions were also useful in this case (Rodrigez et al., 1993; Spoljaric et al., 2012; Bitri et al., 1993). Since the mobility of the $\alpha$-casein and $\beta$-lactoglobulin fractions of cow's milk is significantly higher than that of goat milk, these fractions are also suitable for detection of counterfeiting (Aranda et al., 1988; Cartoni et al., 1999). Based on the $\alpha$ s1-casein fraction of cow's milk, 5-10\% cows' milk mixed with goat milk can be detected, and the same can be said for the $\beta$-lactoglobulin fraction (Cartoni et al., 1999).

In the case of cheese, the $\alpha$-casein fraction is significantly more sensitive than $\beta$-lactoglobulin, as it is eliminated during cheese making, and therefore its concentration is low and tends to precipitate, which, in turn, reduces its amount. The $\alpha$-casein studies are based on the assumption that their concentration is relatively constant in cow's milk, although some studies suggest that there may be large individual variations that affect coagulation, making it difficult to detect less than 5\% cow's milk from goat cheese (Kaminarides \& Koukiassa, 2002; Mayer et al., 1997; Molle \& Leonil, 2005).

The isoelectric focusing following urea extraction of the cheeses allows for a very precise determination of the amount of cow's milk from para- $\kappa$-casein content from goat and sheep cells. Using this method, applying a densitometric evaluation, 1 to $2 \%$ of cow's milk can be detected from sheep's milk and sheep's cheeses (Mayer et al., 1997; Molle \& Leonil, 2005).

HPLC is also suitable for the detection and quantification of a minimum of $2 \%$ cow's milk mixed with goat or sheep's milk (Romero et al., 1996). At least 2.5\% cow's milk from sheep and goat milk can also be detected by immunodiffusion methods and immuno-electrophoresis (Rodrigez et al., 1993; Alava et al., 1998). These methods are also suitable for determining the proportion of cheese from cow's milk if it reaches at least $10 \%$. Radial immunodiffusion was also used to detect cow's milk from sheep's and goat's milk, but this technique did not spread in practice (Mancini et al., 1973). The cow's milk can also be detected from the milk of the other two species with the help of the rocket immunoelectrophoresis, because cross-reactivity is excluded between the antibody and goat milk and by this method the mixing of $1-5 \%$ cow's milk with goat's milk can be detected. The method is applicable to both heat-treated, homogenized and raw milk (Redford et al., 1981).

The ELISA method has also been used with high efficiency for determination of cow's from sheep milk and sheep cheese, although the pasteurized milk and the sterilized milk give a weaker immune response due to the likely precipitation (Hernandez, 1997; Haza et al., 1999; Rodrigez et al., 1993).
Comparing the methods, it can be stated that electrophoresis, especially polyacrylamide gel electrophoresis (PAGE) gives more accurate and reliable results than either immunoelectrophoresis or radial immunodiffusion. By electrophoresis, the mixing of 5\% goat milk into the sheep's milk can be detected with great certainty (Cattaneo, 1989).

\section{Counterfeiting of buffalo milk with cow's milk}

Due to the low price of cow's milk, the water buffalo's milk is often counterfeited with cow's milk during the production of typical Italian mozarella-cheese. Based on electrophoretic mobility, electrophoresis is preferably used to detect cow's milk mixed with buffalo milk (Aschaffenburg, 1963). This is best suited for $\alpha$ - and $\beta$-casein, as their motility differs the most (Albinico \& Resmini, 1967). Of the casein fractions, as1-casein gave the best results both in polyacrylamide gel and agarose gel electrophoresis. Each casein fraction also has a matching pair in cow's milk and buffalo milk that can be separated by isoelectric focusing (IEF) (Krause \& Belitz, 1985).

Attempts were made to use proteolytic enzymes and then to separate the fractions to distinguish the two milks. The electrophoretic mobility of the fractions obtained was also different, which is also useful for detecting cow's milk from buffalo milk (Singhal \& Ganguli, 1965). Experiments have been conducted to analyze $\gamma 2$ and $\gamma 3$ casein fractions after administration of plasmin using PAGE and IEF, which proved to be suitable for detecting $1 \%$ of milk from the other species. The method is suitable not only for detection, but also for quantification using the casein fractions mentioned (Moio et al., 1989).

Attempts have also been made to apply electric conductivity, based on the principle that the electric conductivity of buffalo milk increases proportionally with the addition of cow's milk (El-Shabrawy \& Mehenna, 1980). Determination of the fatty acid composition of the milkfats was attempted on the basis that the palmitic acid and oleic acid content of the milkfat of the buffalo milk has significantly increased in the liquid phase following addition of cow's milk. These two fatty acids react very sensitively to the mixing with cow's milk, and with the help of them, the mixing of 5\% cow's milk with buffalo milk can be detected with great certainty. Since the fatty acid composition is influenced by the season, the region and the animal feed, it may be recommended to make comparisons in all environments regarding the composition of the fats of the two species and to establish a local estimation system to determine the proportion of cow's milk (Farag et al., 1982, 1983, 1984).

A method has been developed with the help of buffalo antibody produced by buffalo casein micelles, and also based on carotene content, which is based on the fact that the carotene content of buffalo milk is significantly lower than that of cow's milk. Buffalo milk contains more lactenin and less agglutinin than cow's milk, which may also be the basis for differentiation (Jairam \& Nair, 1979). 
The different species of milk can be distinguished on the basis of different volatile components. For instance, dimethyl sulfone constitutes $25 \%$ of the total volatile components in cow, goat and sheep milk, while this is only $4 \%$ in buffalo milk, which may also be the basis for distinction. 3Methylbutanal is only present in buffalo milk, phenylacetaldehyde and benzaldehyde are present in high concentrations in goat's milk, while 2-methylketones and 1octene-3-ol are found in higher concentrations in buffalo milk, and phenyl-ethanol is not found in sheep's and goat's milk, it is in a hundred times higher concentration in buffalo milk than cow's milk. All of these can constitute the basis of potential analytical methods (Mojo et al., 1993).

\section{Counterfeit of mother's milk with other milks}

In the flocculation test, a solution of calcium acetate at the correct concentration precipitates the casein proteins at $37^{\circ} \mathrm{C}$ and whey proteins at $60{ }^{\circ} \mathrm{C}$ but does not react with human milk and colostrum (Alison, 1952). If flakes come out of breast milk, it also contains cow's milk. Cow's milk mixed with breast milk can also be detected with saturated copper sulphate solution and $0.4 \%$ cadmium sulphate solution to precipitate in the presence of cow's milk. Dilution of breast milk with water can be detected on the basis of increase in freezing point, but it should be treated with extreme caution because the freezing point can vary from person to person and even from the same mother (Miller \& Ellis, 1953).

Cow's milk mixed with breast milk is relatively easy to detect in breast milk and on the basis of differences in the properties of protein fractions of cow's milk. Since $\beta$-lactoglobulin does not occur in breast milk, its presence in breast milk clearly indicates counterfeiting (Urbanke, 1992). Suitable for the detection of counterfeiting in the whey protein are the fraction $\alpha$ - lactalbumin and casein fraction $\kappa$-casein. Analysing these protein fractions $1 \%$ cow's milk in breast milk can be detected. The methods used are PAGE and IEF.

The free amino acid and taurine content of breast milk is significantly higher than that of cow's milk. While breast milk has a taurine content of $33.5 \mu \mathrm{mol} / 100 \mathrm{ml}$, cow's milk is only $1.9 \mu \mathrm{mol} / 100 \mathrm{ml}$ and for glutamic acid $262.7 \mu \mathrm{mol} / 100 \mathrm{ml}$ and $28.8 \mu \mathrm{mol} / 100 \mathrm{ml}$ respectively. These values also provide an opportunity to detect cow's milk mixed with breast milk, as it significantly reduces both the amount of taurine and free glutamic acid. Both taurine and free glutamic acid can be determined by ion-exchange column chromatography by derivatization with post-column ninhydrin or by HPLC with pre-column derivatization (Mehaja \& Al-Kanhal, 1992).

\section{Soymilk in cow's milk}

Recently, soymilk and soy protein have received great attention from both an economic and nutritional point of view. This is especially true for developing countries, where there is a shortage of high-quality protein of animal origin, for which soy protein can be used to replace or supplement it. In addition, soymilk and dairy-based ingredients made from soymilk are ideal nutrients for vegetarians and people suffering from milk protein allergy (El-Safty \& Mehanna, 1997). It is difficult to find an analytical method to detect cow's milk mixed with soymilk because mixing 10-20\% soymilk with cow's milk did not change the organoleptic qualities of yogurt or cheese. The addition of $20 \%$ soymilk did not change the clotting time, but in this case, even longer clotting times are expected (Sharma et al., 2009; Metwalli et al., 1982).

The similarities in the structure put analysts at a particularly difficult problem when soy protein is to be detected in a dairy product. Several methods have been developed for this purpose: sodium dodecyl sulphate polyacrylamide gel electrophoresis (SDS-PAGE), serological methods and peptide analysis. These analyses are based on differences in the protein content of soymilk and cow's milk. Using PAGE with $\mathrm{pH} 8.6$ tris buffer, six fractions of cow's milk and nine fractions of soymilk can be separated. The soy globulin fractions have higher electrophoretic mobility than the corresponding milk protein, $\kappa$-casein, but less than $\gamma$-casein. This method is suitable to unveil the mixing of $2 \%$ soya milk with cow's milk (Kim \& Park, 1971, 1973). In addition to these methods, PAGE, SDS-PAGE, and HPLC can also be used to identify soy protein and safely detect already $5 \%$ soymilk in cow's milk and quantify it (Espeja et al., 2001).

Evaluating the peaks obtained during the HPLC analysis with a verifying line, more than $1 \%$ soymilk can be detected in cow's milk with great certainty (Hewedy \& Smith, 1989, 1990). The disadvantage of these methods is that they are expensive, require specially trained personnel and expensive instruments, whereas ELISA methods are significantly cheaper and also can detect more than 1\% soymilk in cow's milk. In addition to soymilk determination, these methods can also detect coconut milk mixed with cow's milk (Krusa et al., 2000; Hewedy \& Smith, 1990).

\section{Detection of whey and buttermilk from milk}

Increased cheese consumption has increased the amount of whey that is difficult to store and use. Whey powder made from whey is significantly cheaper than skimmed milk powder, but its use due to its high milk sugar content is limited (Cartoni et al., 1999). The skimmed-milk powder may, as required, only be made from skimmed milk and must not contain any dry matter from whey or buttermilk, nor contain inoculation enzyme. In many parts of the world, the buttermilk left behind after the production of sweet cream butter is mixed in powder form with skim milk powder, for the detection of which several methods have been developed (Greenberg \& Dower, 1986). Counterfeiting can be tracked by the amount of whey protein fraction, the amount of lactic acid, which is positive if it exceeds $150 \mathrm{mg} / 100 \mathrm{~g}$ and the ash content, which is positive if it is more than $8 \%$.

The electron microscope can also be used to detect the buttermilk powder because the surface of the particles is different if the powder is made from skim milk or from buttermilk. The acid precipitation test can also be used, in 
which casein micelles, whey proteins and large amounts of fat-ball membranes in the buttermilk behave differently.

Counterfeiting of pasteurized milk is also a major problem in different countries (Chavez et al., 2008). Because the price of whey is low, its organoleptic properties are not significantly different from those of milk, it is clear that counterfeiting of milk can generate significant economic benefits. The amount of whey in the milk can be detected by the ratio of casein to whey protein. Casein can be determined after precipitation at $\mathrm{pH} 4.6$, which remains after that, is the whey protein. Casein content and phosphorus content are very closely related, because only casein is able to bind phosphate with an ester bond, therefore the phosphorus content is related to the casein content, which can indicate the counterfeiting of milk with whey (West, 1986).

\section{Whey-protein in dairy products}

It is very important to know how many milk solids are contained in the various dairy products, and how much milk powder they contain (Fereira \& Oliveira, 2003). Frozen dairy products should contain at least $10 \%$ fat and $20 \%$ dry matter, and the proportion of whey protein and casein should also be known. The dye-binding methods are suitable for the determination of the protein content of ice creams but give a slightly different result than the traditional Kjeldahl method. It is very difficult to separate casein from whey protein because it precipitates together after various heat treatment processes, practically inseparable (Edith et al., 1994).

In order to identify these two proteins, the complex should be disrupted or some other solution, such as estimates based on phosphorus content. Since phosphorus only binds to casein, the amount of casein can be estimated based on the phosphorus/nitrogen ratio, even in a complex matrix like ice cream (Douglas et al., 1982). In addition, radial immunodiffusion can be used to estimate the amount of casein and whey protein. The determination of the amount of casein on the basis of the phosphorus content is useful for sodium caseinate and processed dairy products (Miralles et al., 2000). Addition of whey powder, buttermilk powder or caseinate to skimmed milk can be detected by cysteine cystine (-S-S-) complex and sialic acid. The cysteine and cystine content can be measured by a modified ninhydrin reaction or ion exchange column chromatography. The amount of $\mathrm{SH}$ groups in the normal skimmed milk powder is $86.4 \mu \mathrm{g} / \mathrm{g}$ protein, which shows a linear increase in the addition of whey or whey protein. Addition of $10 \%$ whey protein to lean milk powder significantly increases the concentration of SH groups, so the amount of added whey or whey protein can be determined by this method (WolfschoonPombo \& Furtado, 1989). If the cysteine/cystine ratio is greater than three and the amount of sialic acid exceeds $3 \%$, the whey protein supplement is proven. It is also possible to use HPLC and gel electrophoresis, but these are expensive technique (Ferreira \& Oliveira, 2003; Recio et al., 1996, 2000; Risco et al., 2000).
The amount of added whey protein can also be determined on the basis of the amino acid composition if it reaches or exceeds $10 \%$. This method is not affected by the fact that it is denatured or intact whey protein, or whether or not heat treatment has been applied. There have also been attempts to determine the glyco-macropeptides by HPLC or spectrophotometry, but due to bacterial contamination, there was a lot of false results (Simona, 2009). Good results were obtained by detecting the mixing of whey powder produced with rennin mixed with sweet buttermilk powders, but the results were even better for the whey powder obtained by sour curdling (Greenberg \& Dover, 1986).

Comparing the methods, the HPLC method surpasses all the others both in reliability and sensitivity, and the mixing of $0.5 \%$ sweet whey powder can be detected by analyzing the protein fractions (Lechner \& Klostmeyes, 1981; Potgieter, 1985).

The sweet whey powder produced during cheese making contains more water-soluble molecules than milk, which means higher lactose, sodium, potassium and chloride content. Therefore, it is clear that the freezing point of milk made from milk powder will be significantly lower if whey powder is added. From the reduced freezing point, by the use of regression equations, the amount of added whey powder can be determined (Castaneda et al., 1987).

Other methods are known for the determination of added whey powder, but these require complex preparation and are therefore not widespread in practice. Infrared spectroscopy, in combination with Fourier formations, can be used to differentiate proteins (Mendenhall \& Brown, 1991).

\section{Milk produced from milk powder (reconstituted)}

In the production of milk powder, some of the proteins are denatured, which can be used to detect reconstituted milk. Dye-binding methods and gel electrophoresis were not able to distinguish between normal and recycled milk. However, based on the ratio of $\beta$-casein to $\alpha$-lactalbumin, mixing $25 \%$ of reconstituted milk with normal milk can be detected (Ju et al., 1981; Resmini et al., 1996; Chen \& Ji-Hong, 1992).

Electron microscopy revealed that the reconstituted milk contains aggregates with a diameter greater than $500 \mathrm{~nm}$ that do not occur in normal milk (Resmini et al., 1996). Resazurin was also applied, which gives a different colour to the two milks, and attempts were made to use all the reducing capacity of the milk for this purpose. It is believed that the density and the freezing point correspond to the expected value, the nitrate content of the reconstituted milk, due to the nitrate content of the dilution water used, will be higher than that of normal milk, since the nitrate content of normal milk is extremely low. If the nitrate content is greater than $1 \mathrm{mg} / \mathrm{kg}$, it is suspected that the milk contains recycled milk. During the determination, nitrate is converted to nitrite, which can be accurately measured by chemiluminescence (Doerr et al., 1982). 


\section{Other options for milk and milk product counter- feiting}

If the manganese content of the milk is high, we can suspect that the milk has been falsified with calf feed, as the manganese content of the calf feed can reach $10-15 \mathrm{mg} / \mathrm{kg}$, while the milk contains only $0.021 \mathrm{mg} / \mathrm{kg}$. The addition of pure milk to milk containing plant proteins can be detected by measuring the whey protein nitrogen after casein precipitation (Vannini, 1984).

Mixing raw milk with pasteurized milk can be detected by measuring the activity of the phosphatase enzyme (Csapó \& Salamon, 2006). The authenticity of mozzarella cheese can be checked with a scanning electron microscope, as fakes contain grease balls that cannot be detected in the original cheese.

Glucose, cane sugar, urea or ammonium sulfate are added to the milk to mask the dilution with water. These materials can prevent even the freezing point growth, so sophisticated analytical methods are needed to detect fraud. The sugar added to the milk can only be analyzed by chromatographic methods, primarily by HPLC, because of the milk sugar originally present in the milk, and not the total amount of sugars, but the sugars are determined individually (Reineccius et al., 1970). The method is quick to digest sugars with invertase enzyme, and the glucose and fructose produced are determined enzymatically by glucose oxidase peroxidase test.

Adding salt to milk up to $0.4 \%$ does not cause a change in the taste of the milk, but at the same time, $13 \%$ water can be added to the milk without significantly changing its freezing point. Ammonia solution is also added to the milk to reduce acidity, occasionally sodium bicarbonate or antibiotics to keep it for longer. Addition of $0.3 \%$ sodium bicarbonate allows the milk to be diluted by $10 \%$ with water without significant changes in measurable parameters (Navale \& Gupta, 2016).

\section{Other fats in milk, butter, and ghee}

Since the milkfat is one of the most expensive fats, it's counterfeiting with other cheap fats occurs almost everywhere in the world. Most of all, vegetable oils, including linseed oil and beef tallow, are used to the greatest extent for counterfeiting. In most countries, a variety of methods have been developed to detect butter counterfeiting. Most of the methods are based on the analysis of the structure of triglycerides, the analysis of fatty acid composition, the measurement of unsaponifiable lipids (sterols, sterol esters, tocopherols, carbonyl compounds), or the analysis of physical properties (Alonso et al., 1997; Barui et al., 2012).

The most promising method is based on the analysis of triglycerides, with the help of triglycerides with different carbon numbers, that the milk fat can be well separated from other fats and the addition of $5-10 \%$ foreign fat can be detected with great certainty. Various formulas have been developed to help detect not only the falsification but also the type of fat that has been fake. These methods are based on the fact that only the milk fat contains butyric acid, capric acid, caprylic acid, and caprine acid, so triglycerides with lower carbon numbers are present in much higher concentrations than other fats (Fauconnot \& Dionisi, 2006; IDF 2010; Ulbert, 1994). However, the results obtained should be handled with care, because not only the fatty acid composition but also the composition of the triglycerides can vary according to the season, region and lactation status. Winter milk contains more short and medium-chain triglycerides, than summer milk. Ultraviolet light absorption did not succeed in detecting vegetable oils from milk fat, but the concentration of butyric acid proved to be successful. For this purpose, gas chromatography (GC) was applied to determine not only the fatty acids but also the different positional isomers (cis, trans, cis-trans, cis-cis, trans-trans, etc.) using a capillary column. Infrared spectroscopy was also used to identify the latter (Garcia et al., 2012; Guittirez et al., 2009).

Infrared spectroscopy of trans unsaturated fatty acids, e.g. they were able to detect cottonseed oil mixed with $0-30 \%$ butter. Trans unsaturated fatty acids naturally occur in milk fat, but they are not found in natural, non-hydrogenated (catalytic hydrogenation) vegetable oils, so measurement of trans unsaturated fatty acid concentrations also provides the opportunity to detect butter counterfeiting. These results should also be treated with caution, because the amount of trans fatty acids may be influenced by the trans fatty acid content of the feed and the biohydrogenation processes in the beef rumen (Parodi \& Dunstan, 1971). The rumen microorganisms are able to saturate the unsaturated fatty acids, synthesizing trans isomers from the cis isomers, and produce conjugated double bonds from the isolated double bonds, cis9, trans11 conjugated linoleic acid (and other positional isomers) considered to be extremely useful for humans (Csapó \& Varga-Visi, 2014).

During the certification, fatty acids are used to determine the different indices for pure, unadulterated milk fat, and then, when comparing the fatty acid composition of the counterfeit sample to the composition of the pure sample, the falsification can be proven, and even information regarding materials used for the falsification of butter can be obtained. In Japan, butyric acid and capric acid, as well as cholesterol, are determined by gas chromatography, and the data is used to infer counterfeiting. On the basis of the ratio of butyric acid/caproic acid, counterfeiting can also be detected by the addition of butyric acid trans-esterified beef or coconut fat to the butter (Farag et al., 1983; Kamm et al., 2002).

Although seasonal and geographical differences may be relevant to the composition of milk fat, these differences, however, are almost negligible when comparing the fatty acid composition of butter and other fats and oils used for counterfeiting (Alonso et al., 1997; Herman-Lara et al., 2017). The ratios of lauric acid/capric acid, myristic $\mathrm{acid} /$ capric acid and myristic acid/lauric acid are particularly 
useful for detecting butter counterfeiting. The following oils and fats are used regularly to counter butter.

Vegetable fats. The fatty acid composition, the monoglyceride and triglyceride content of the milk fat is so different from the other fats that it is not only vegetable fats but also animal fats used for counterfeiting can be detected by measuring these components (Toppino et al., 1982). Considering the differences between varieties, climatic conditions and geographic location, the vegetable fat in the butterfat can be demonstrated with great certainty based on the lauric acid/capric acid ratio. Already $10 \%$ coconut fat, palm oil or rapeseed oil, or $5 \%$ soy oil in milk fat based on the content of long and medium carbon-chain triglycerides can be identified (Alonso et al., 1997).

Partially hydrogenated vegetable fats from the cheese can be detected by gas chromatography, based on the fatty acid composition. Of the fatty acid indices, the ratio of butyric acid to oleic acid was the most sensitive to counterfeiting, because vegetable oils contain a lot of oleic acid and virtually no butyric acid. This method is not applicable to coconut fat, which contains relatively little oleic acid (Fox et al., 1988, 1989).

The ghee is also falsified with vegetable fat from the fruit of the phulwara tree grown in India because its color and texture are very similar to butter, but its price is considerably lower. The amount can be measured by TLC analysis of triglycerides. Because it is a vegetable fat, cholesterol content can also be the basis for detecting counterfeiting. The measurement of cholesterol or phytosterol may be suitable for detecting any vegetable fat because the majority of the sterol content of butter (more than 99\%) is cholesterol and no other type of sterol compound is practically present in it. Cottonseed oil contains mainly $\beta$-sitosterol (Kamm et al., 2002), but it also contains $\gamma$-sitosterol and stigmasterol, so the falsification with vegetable oils is clearly indicated by the decrease of cholesterol concentration and an increase of plant sterols in counterfeit food (Homberg \& Bielefeld, 1979). Refining, deodorizing and steaming the fats do not affect the method, animal fats with similar cholesterol content can not be detected by this method from milk fat. More than $2 \%$ corn oil or rice oil, more than $5 \%$ cocoa butter, rapeseed, sesame, soybean or peanut oil, more than $20 \%$ coconut fat or palm oil, or more than $35 \%$ palm kernel oil can be identified with this method from the butter (Huygheabert \& Moore, 1974). Garcia et al. (2012) used the MALDI-QTOF MS techniques with good efficiency for identification of counterfeiting the milk powder with plant oils and fats.

The ratio of total hydrocarbons to total sterols in the unsaponifiable fraction is quite different in bacon, margarine, and ghee, so this can also be the basis for detecting counterfeiting. Bacon and margarine contain 20 to 30 times more hydrocarbons than cattle ghee and 10 to 15 times as much as ghee made of buffalo milk. Based on the above, using the regression equations edited, the grease and margarine mixed with ghee can be shown with great security (Farag et al., 1982).
Various vegetable oils contain compounds that are only found just in that oil and nowhere else. Such compounds are sesamin and sesamol in sesame oil, the detection of which clearly refers to counterfeiting, which is confirmed even by the high tocopherol content. Differential scanning calorimetry and differential thermal analysis may also refer to counterfeiting, but these methods have not spread in practice. Alcohol-soluble and alcohol-insoluble triglyceride content is also suitable for differentiation to detect counterfeiting (Keeney et al., 1971).

\section{Animal fats and fats of marine origin}

Detecting animal body fat in butter is difficult because these fats have very similar properties. An interesting case confirms this, when buffaloes, fed with cottonseed cake, will have their milk fat similar to that of butter counterfeited with animal fat. It is very difficult to detect animal fat in milk fat, so several methods have been developed and applied with moderate success for this purpose (Precht, 1991, 1992a,b).

Attempts have been made to reveal counterfeiting based on the different solubility of butterfat and animal fat in a $3: 4$ mixture of acetic acid : ethyl alcohol, by measuring the "butyric acid number",analysing the critical melting temperature (ghee 49.5-53.5 ${ }^{\circ} \mathrm{C}, \quad 70-73{ }^{\circ} \mathrm{C}$ tallow), by measuring the fat content precipitated and not precipitated by urea, by fluorescence, in which the counterfeit ghee shows blue fluorescence while the original shows an authentic pale green fluorescence, and even various chromatographic techniques were applied. The essence of these latter techniques is that either the triglycerides or a fraction, but most often the fatty acid composition was determined on the basis of which, by making indices, it was possible to estimate the various fats mixed with the butter (Precht, 1992a,b; Toppino et al., 1982).

From the point of view of applicability, among these indices are the stearic acid/oleic acid ratio, the ratio of total saturated and total unsaturated fatty acids, the ratio of palmitic acid to stearic acid, and the ratio of saturated to unsaturated triglycerides are most important (Precht \& Heine, 1986). Attempts have been made by enzymatic methods, namely the analysis of free fatty acids remaining after the use of the lipase enzyme, as well as the determination of 2monoacylglycerol, which is based on the principle that the lower fatty acids in the triglycerides are less resistant to the attack of lipase than long-chain ones (Lipp, 1996a,b). By analyzing the UV spectrum, butter and lard can be separated in the 220-420 nm range, while butter and tallow cannot be distinguished (Colombini \& Amelotti, 1979).

After separation by chromatography, the fish oil is easily separated from the butter by a different fluorescent signal. By distillation of the volatile fatty acids and by chromatography, it was easy to separate and distinguish between 5-20\% dolphin oil from the butter (Bottini \& Campanello, 1955). Counterfeiting of butter with triacetin (glycerol triacetate) or hydrogenated dolphin oil could be detected by measuring the conductivity of the volatile distillate, as the conductivity of 
the pure butter was lower than that of the counterfeit caused by higher concentrations of acetic acid and isovaleric acid in the dolphin oil (Zachar et al., 2011).

\section{Other counterfeits}

The butter is counterfeit even if it is made from milk of different animal species or if the milk fat itself is modified by some technological intervention. If the butter is produced from mixed milk from different ruminant species, it is almost impossible to detect, because even the gas chromatographic fat analysis is not sensitive to distinction. Hydrogenated vegetable oils are used in large quantities in India to falsify ghee with this cheap food (Baruah \& Chakroworthy, 1980). Since the degree of hydrogenation is now well controlled, it is difficult to detect such counterfeiting even with sensitive GC methods (Al-Khalifah \& Al-Kathani, 1993; Antony et al., 2018).

\section{Dilution of milk with water and its detection}

Milk watering can easily be detected by determining the freezing point, as the water causes the initial freezing point of milk to increase. With a thermistor cryoscope, based on the freezing point, three percent of the water added to the milk can be detected with great certainty (Skrinjar, 1984).

The most commonly used tool for determining the freezing point of milk with the Beckmann cryoscope is the freezing point of the milk with a precision of one-thousandth centigrade. The freezing point of milk varies between -0.53 and $-0.56{ }^{\circ} \mathrm{C}$. If the freezing point of milk is greater than $0.53{ }^{\circ} \mathrm{C}$, the milk is considered to be counterfeited with water. As the freezing point of milk increases from $-0.53{ }^{\circ} \mathrm{C}$ to -0.27 ${ }^{\circ} \mathrm{C}$, the dilution rate can be around 2 to 50 percent, so this method can not only detect the fact of counterfeiting but also provide information on the amount of water added (Hanus et al., 2011; Zagorska \& Ciprova, 2013; Henno et al., 2008; Kessler, 1984; Kessler \& Horak, 1984).

Milk osmotic pressure is mainly due to lactose (4.6 to $4.9 \%$ in cow's milk) and secondly to sodium and potassium and then to all other minerals, as the effect of other components on pressure is negligible. If the lactose is hydrolyzed to glucose and galactose, it will significantly reduce the freezing point $\left(-0.274{ }^{\circ} \mathrm{C}\right)$ and increase the osmotic pressure. Therefore, if the lactose is hydrolyzed, the forgery of milk with moderate amounts of water, as the freezing point does not change, cannot be detected (ISO, 2009).

Surface tension and viscosity measurements, the absorbance of the filtrate remaining after trypsin digestion and trichloroacetic acid precipitation at $280 \mathrm{~nm}$, and the analysis of nitrate ions, which is a clear indication of dilution, were also used to detect milk dilution. The refractometric analysis of the filtrate remaining after ultracentrifugation can be used to detect the dilution of the breast milk. They also used the thermistor cryoscope or the vapor pressure thermometer to detect the dilution with water, but these methods were not used in practice (Csapó \& Csapóné, 2009b).

\section{Determination of heat treatment of milk and dairy products}

The milk must be heat-treated in order to eliminate possible pathogenic micro-organisms. In the dairy industry today, almost all milk and dairy products undergo some kind of heat treatment and produce only a small proportion of conventional dairy products from raw milk. Sometimes heat treatment is not enough to kill pathogenic germs, and sometimes, with technology deficiencies or intentionally, raw milk is mixed with pasteurized milk, which can be detected by the following rehearsals to estimate the degree of counterfeiting (IDF, 2008).

The Storch-method can be used to detect deficiencies in heat treatment or lack of heat treatment for milk or cream made from milk, sour milk and milk products, cottage cheese, and goat cheese, which have been heat-treated for more than 15 minutes at $80^{\circ} \mathrm{C}$ or $75^{\circ} \mathrm{C}$. The essence of the method is that the raw peroxidase enzyme in raw or inadequately heattreated milk or in the product of such milk breaks down the hydrogen peroxide and the liberated atomic oxygen oxidizes the N,N-diethyl-1,4-phenylenediamine hydrochloride to a blue-grey colored compound (Kessler, 1984; Marks et al., 2001).

Quantitative determination of the phosphatase enzyme can be used for milk that has undergone heat treatment at temperatures below $80^{\circ} \mathrm{C}$ or at a temperature above $75^{\circ} \mathrm{C}$ for less than 35 seconds, or at $65^{\circ} \mathrm{C}$ for 30 minutes, and for dairy products made from such milk (Birlouez-Aragon et al., 2002). In raw or inadequately heat-treated milk, or in pasteurized milk mixed with raw milk or in a milk-based product, the phosphatase enzyme hydrolyzes disodium phenyl phosphate, and the phenol released during hydrolysis reacts with 2,6dibromoquinone chlorimide yielding a blue color, which is proportional to the free phenol, can be measured photometrically (Grazina et al., 2010; EN ISO 11816).

In the heat-treated milk mixed with raw milk or insufficiently heat-treated milk or the dairy product made from such milk, the phosphatase enzyme releases the ortho-cresolphthalein from the hydrogen ortho-cresolphthalein phosphate, which with alkali gives a lilac-purple coloration. The color indicates that the sample shows a phosphatase enzyme and the sample did not receive the desired heat treatment (Rocco, 1990).

\section{Detection of inflammatory udder milk}

Suitable for this purpose are the mastitis test and the Whiteside test, which indicate the quantitative relationship of cells with nucleus in the milk (epithelial cells, leukocytes), because the reagent releases the deoxyribonucleic acid in the nucleus and the intensity of the reaction depends on the amount of DNA (Godden et al., 2017). Within three to five days after calving, and during the last month of lactation, the epithelial cell content of milk is higher, so a positive reaction at this time does not indicate a mastitis (Bhutto et al., 2012). The two tests cannot be used for diagnostic purposes, however, the examination of the milk of the cow livestock 
may be advantageous, since even a little reaction from the mixture indicates mastitis and the insufficient udder health among the animals (Rossi et al., 2018).

\section{Detection of the amount of spoiled milk that is unfit for consumption}

The alizarin test is suitable for this purpose, which is based on the determination of the acidity and the $\mathrm{pH}$ changes of the milk. The test can be used to separate the milk from the inflammatory udder in the barn, but it is also suitable for tracking changes during transport or storage. Since the proteins in the milk also lose their original form due to the increase in acidity, the $\mathrm{pH}$ change may also indicate whether the milk is suitable for production of dairy products such as UHT milk or milk powder. From the reaction of the alizarin indicator and the milk we can conclude whether the $\mathrm{pH}$ of the milk has changed in the acidic or alkaline direction and how the change affects the technological properties of the milk (Kartheek et al., 2011; Csapó et al., 2016).

\section{Discussion and conclusions}

In the media, news about counterfeiting of food can be found almost daily. There is no food that fraudsters have not tried to forge, and unfortunately, the counterfeiters are always one step ahead of those who want to unveil them. Counterfeiting occurs in many types and sophisticated ways can only be combated if anti-counterfeiting organizations are established everywhere in the world, national anti-counterfeiting strategies are drawn up when official measures are taken to detect counterfeiting, when strict sanctions are applied and where food counterfeiting is strictly punished in proven cases. Counterfeiting can only be combated effectively through international cooperation, coordination of strategies and measures, and regular recurring control actions. If all these things work, they work well, but we can't be sure that if we go to a supermarket, we won't take some fake food off the shelf. With conscious customer behaviour, buying in a trusted place, we can do our best to avoid buying fake foods.

Certain easy-to-counterfeit foods occurred in the past, but also in the present, large quantities, are counterfeited especially where counterfeiting promises significant financial benefits. In most cases, these counterfeits only impair the quality of the food, so sometimes they do not get the attention they deserve, but some of the counterfeits can be lifethreatening, and, in many cases, such counterfeits have required many lives. Such cases include counterfeiting of vodka with methyl alcohol, counterfeiting of wine with ethylene glycol, falsification of ground red paprika with lead oxide or lead chromate, or counterfeiting of infant formula with melamine. In counterfeiting, the ingredients in the food are deliberately replaced, modified, or lost from the ingredients without being brought to the attention of the consumers. The cause of counterfeiting is, in almost every case, material gain. Counterfeiters are not interested and sometimes unaware of the consequences of consuming their products, with the sole aim of maximizing profit. Fake components are often unknown, so they are often difficult to discover.

In the second part of this review article about counterfeiting of milk and dairy products, we show that counterfeiters are always one step ahead of control experts, but with the development of analytical chemistry and food analytics, methods have been developed to uncover and punish counterfeiters so that the occurrence of counterfeits can be reduced. We wanted to draw attention to the extent of food counterfeiting, the various methods of counterfeiting, conscious buying, and protection of consumers from poor quality food and counterfeits.

\section{Acknowledgements}

The work/publication is supported by the EFOP-3.6.3VEKOP-16-2017-00008 project. The project is co-financed by the European Union and the European Social Fund.

\section{References}

2004. Hungarian law No. XVIII. about viticulture and oenology 2004. 19.

Albert, Cs. - Csapó, J. (2014): Food counterfeiting, past, present and future (in Hungarian). Acta Scientiarum Trasylvaniae, Chimica. 2013-2014. 21-22/3. pp. 60-69.

CTV News (2008): China: 'Out of control' dairy system led to abuse. 2008. Associated Press. September 23. 1.

https://www.ctvnews.ca/china-out-of-control-dairy-systemled-to-abuse-1.327301

Bueno, L. - de Araujo, W. - Salles, M. - Kussuda, M. Paixão, T. (2014): Voltammetric electronic tongue for discrimination of milk adulterated with urea, formaldehyde and melamine. Chemosensors. 2014. 2. 4. pp. 251-266. https://doi.org/10.3390/chemosensors2040251

Buglass, A.J. Handbook of alcoholic beverages. Technical, analytical and nutritional aspects. John Wiley \& Sons. 2011. pp. 1-1167.

Cayuela-Sánchez, J. A. - Caballero-Guerrero, B. Fresh extra virgin olive oil, with or without veil. Trends in Food Science and Technology. 2019. 83. pp. 78-85.

Chousou, C. - Tsakiridou, E. - Mattas, K. Valuing consumer perceptions of olive oil authenticity. Journal of International Food \& Agribusiness Marketing. 2018. 30. 1. pp. 1-16. https://doi.org/10.1080/08974438.2017.1382418

Chui, T. (2010): Laws urged to prevent organic food fraud. China Daily. 2010. May 15. 1. 
Cox, J. (1999): From vines to wines. The complete guide to growing grapes and making your own wine. Versa Press. United States. 1999. pp. 1-235.

Csapó J. - Albert Cs. - Csapóné Kiss Zs. (2008): Food analytics. Selected chapters. (In Hungarian). Scientia Publishing Co., Kolozsvár (Cluj-Napoca), 2008. pp. 1-314.

Csapó J. - Csapóné Kiss Zs. - Albert Cs. - Salamon Sz. (2007): Certification of Food Proteins (In Hungarian). Scientia Publishing Co., Kolozsvár (Cluj-Napoca), 2007. pp. $1-506$.

Csapó J. - Csapóné Kiss Zs. (2006, eds): Certification of Food \& Feed Proteins. (In Hungarian. Co-authors: Babinszky L. - Győri Z. - Simonné Sarkadi L. - Schmidt J.). pp. 1-451. Mezögazda Publishing Co. Budapest.

Csapó J. - Csapóné Kiss Zs. (2009): The most important nutritional components of cow's milk. I. Protein and amino acid composition, fat content and fatty acid composition. In: The role of milk in human nutrition. (In Hungarian. Editor: Kukovics, S.) Melánia Publishing Co. Budapest. pp. 147-165.

Csapó J. - Csapóné Kiss Zs. (2009): The most important nutritional components of cow's milk. II. Contents of lactose, minerals and vitamins. In: The role of milk in human nutrition. (In Hungarian. Editor: Kukovics, S.) Melánia Publishing Co. Budapest. Budapest. pp. 167-186.

Csapó J. - Csapóné Kiss Zs. (2002): The role of milk and dairy products in nutrition. In Hungarian. Mezögazda Publishing Co. Budapest, pp. 1-464. ISBN: 963-9358-68-1

Csapó J. - Csapóné Kiss Zs. (2007): Biochemistry - for animal breeders. In Hungarian. Mezögazda Publishing Co. Budapest Budapest. pp. 1-378. ISBN: 9789632863948

Csapó J. - Csapóné Kiss Zs. (2004): Food Chemistry. In Hungarian. Mezögazda Publishing Co. Budapest, ISBN 978963-286-642-0. pp. 1-492.

https://www.tankonyvtar.hu/hu/tartalom/tamop 425/2011 00 01 521 Elelmiszer kemia/adatok.html

Csapó J. - Salamon R. (2006): Dairy technology and quality control. In Hungarian. Scientia Publishing Co. Kolozsvár (Cluj-Napoca), pp. 1-164. ISBN: 978-973-1970-80-6

Csapó J. - Schäffer B. (2001): The properties of milk. In Hungarian. In: Dairy Economics. Tejgazdaságtan. Editor: Szakály S. Dinasztia Publishing Co. Budapest. pp. 64-82. ISBN: 9636573336

Csapó J. - Vargáné Visi É. (2014): Fermented foods and health. 4 Conjugated linoleic acid (CLA) production in fermented foods. Woodhead Publishing Series in Food Science, Technology and Nutrition. pp. 75-105.

Csapó J. (2004): Biochemistry. In Hungarian. Scientia Publishing Co. Kolozsvár (Cluj-Napoca); pp. 1-468.
Csapó J. Separation and determination of the amino acids from wine by ion exchange column chromatography applying postcolumn derivatization. ERASMUS LLP - The intensive program Ecovitis. Sienna, Italy. 2010. July 8-27. pp.1-38.

Csapó J. (2016): Myths about food consumption, or why is red wine a functional food? In Hungarian. HungarianRomanian Friendship Society. 2016. February 18. (68 slide).

Csapó J. (Editor; 2014): Dairy Technology. Milk and milk products in nutrition. In Hungarian. Scientia Publishing Co. Kolozsvár (Cluj-Napoca); (Co-authors: Fenyvessy J. Csanádi J. - Csapóné Kiss Zs.) pp. 1-424.

Csapó J. - Albert Cs. (2017): Functional foods. In Hungarian. Debrecen University Press pp. 1-354.

https://teljesitmenyfokozosporttaplalkozas.blog.hu/2018/10/ 08/csapo janos albert_csilla funkcionalis elelmiszerek

Csapó J. (2000): Our food. Basic foods. Milk and milk products. In Hungarian. In: The Health Book of Nutrition. Ed. Hajós Gy. - Zajkás G., Kossuth Publishing Co., Budapest, pp. 131-143.

https://www.tankonyvtar.hu/en/tartalom/tkt/tejtejtermekek/bi01.html

Csapó J. - Albert Cs. - Csapóné Kiss Zs. (2016): Food Counterfeiting. In Hungarian. Debrecen University Press, 2016. pp. 1-217. ISBN 978-963-473-936-4

Csapó J. - Csapóné Kiss Zs. (2016): Food Chemistry. In Hungarian. Mezögazda Publishing Co., Budapest. pp. 1-492. https://www.tankonyvtar.hu/hu/tartalom/tamop425/2011_00 01_521_Elelmiszer kemia/adatok.html

Csapó, J. - Albert, Cs. (2018): Wine adulteration and its detection based on the rate and the concentration of free amino acids. Acta Agraria Debreceniensis. 2018. pp. 139151.

Csapó, J. (2011): Amino acids in wine. May this be a possible fingerprint of wines? International Conference of Environmental Technologies, Sustainable Agriculture and Regional Development. Hungary, Gyöngyös. 2011. June 0612. $1-30$

Csapó, J. - Albert, Cs. - Csapó-Kiss, Zs. (2013): Detection and determination of sugars in wine. Ecocycles Erasmus intensive programme on sustainable development through ecological cycles. Palermo, Italy. 2013. July 14 - Aug. 4. 146.

Csapó, J. - Csapó, J. - Albert, Cs.- Csapó-Kiss, Zs. (2013): Separation and determination of the amino acids and biogenic amine content of wine by ion exchange column chromatography applying postcolumn derivatization. Ecocycles Erasmus intensive programme on sustainable development through ecological cycles. Palermo, Italy. 2013. July 14 - Aug. 4. 1-70. 
Csapóné Kiss Zs. - Kukovics S. - Csapó J. (2009): The most important nutritional components of sheep and goat milk. In: The role of milk in human nutrition. (In Hungarian. Editor: Kukovics, S.) Melánia Publishing Co. Budapest. pp. 187206.

Csóka, M. (2014): Investigation of color and aroma properties of paprika powder. Corvinus University, Food Scienece Doctoral School, Budapest. pp. 1-240. PhD thesis. http://phd.lib.uni-corvinus.hu/794/1/Csoka_Mariann.pdf

Ebeler, S.E. - Takeoka, G.R. - Winterhalter, P. (2011): Progress in authentication of food and wine. ACS Symposium Series: American Chemical Society. Washington DC. pp. 1377.

https://doi.org/10.1021/bk-2011-1081

El Safty, M.S. - Mehanna, N.: Studies on the use of soymilk in Ras [Egyptian hard type] and Cheddar cheeses making. Egyptian Journal of Dairy Science. 1977. 5. pp. 254-267. El Sheikha, A.F. (2019): DNA Foil: novel technology for the rapid detection of food adulteration, Trends in Food Science \& Technology, In press.

European Union Intellectual Property Office Europol and Eurojust (2016): Knowledge and Awareness Buildig Conference. Counterfeiting of foodstuffs, beverages and agricultural products. Executive summary. 2016. 1-28.

https://euipo.europa.eu/tunnel-

web/secure/webdav/guest/document_library/observatory/do cuments/Knowledge-building-

events/Counterfeiting of foodstuff en.pdf

Everstine, K. - Spink, J. - Kennedy, S. (2013): Economically motivated adulteration (EMA) of food: Common characteristics of EMA incidents. Journal of Food Protection, 2013. 76. 4. pp. 723-735.

https://doi.org/10.4315/0362-028X.JFP-12-399

Fortin, N. D. (2017): Food regulation. Law, Science, Policy and Practice. John Wiley \& Sons, New Jersey. pp. 1-507. ISBN: 978-1-118-96447-7

Gerbig, S. - Neese, S. - Penner, A. - Spengler, B. - Schulz, S. Real-time food authentication using a miniature mass spectrometer. Analytical Chemistry, 2017. 89. 20. pp. 1071710725.

https://doi.org/10.1021/acs.analchem. $7 b 01689$

Fake wine at the winemaker of the year. Weekly World Economy. 2009. September 30.

https://hvg.hu/itthon/20090930_egri_bikaver_vincze_borasz at 1 .

Hammond, D.A. (2012): How to protect your industry from food fraud. EQCS - An example of Industry working together for everyone's benefit! Eurofins. 2012. 1-51.

Handford, C.E. - Campbell, K. - Elliott, C.T. (2015): Impacts of milk fraud on food safety and nutrition with special emphasis on developing countries. Comprehensive Reviews in Food Science and Food Safety. 2015. 15. 1. pp. 130-142. https://doi.org/10.1111/1541-4337.12181

Herman-Lara, E. - Tejeda-Paz, M. - Martínez-Sánchez, C.E. - Rodríguez-Miranda, J. - Ramírez-Rivera, E.J. Hernández-Santos, B. - Juárez-Barrientos, J.M. (2017): Differential scanning calorimetry coupled with chemometric tools for determining adulteration with vegetable fat in fresh cheeses, LWT - Food Science and Technology. 85. pp. 269274.

https://doi.org/10.1111/joss. 12479

Herpai Z. - Szigeti, J. - Csapó, J. (2013): A rapid and sensitive method for the detemination of high-fructose corn syrup (HFCS) in honey. Acta Universitatis Sapientiae, Alimentaria. 2013. 6. pp. 5-13.

Hoorfar, J. - Jordan, K. - Butler, F. - Prugger, R. (2011): Food chain integrity. A holistic approach to food traceability, safety, quality and authenticity. Woodhead Publishing Limited. pp. 1-367.

Hoorfar, J. (2012): Case studies in food safety and authenticity. Lessons from real life situations. Woodhead Publishing Limited. pp. 1-360.

Kasza, Gy. (2009): Risk communication in the field of food safety. Doctoral dissertation. In Hungarian. Corvinus University of Budapest, Doctoral School of Landscape Architecture and Landscape Ecology. 158/2009

King, L.W. - Brians, P. (2015): The code of Hammurabi (18th century BCE). Washinton State University. The website of professor Paul Brians. 2015. 1.

Kirsch, A. (2016): Wines of the Guardian Region (Örvidék). Wine production in today's Burgenland. In Hungarian. Rubicon Historical Magazine. 2016. pp. 56-61.

Kovács B - Csapó J. (2015): Analytical methods for food determination. In Hungarian. University of Debrecen, Faculty of Agriculture, Food Science and Environmental Management. Made within the framework of TAMOP4.1.1.C-12/1 / KONV-2012-0014. project. ISBN 978-963473-831-2. 2015. pp. 1-252.

Kovács B - Csapó J. (2015): Modern methods of food analysis. University of Debrecen, Faculty of Agricultural and Food Science and Environmental Management. Made within the framework of TAMOP-4.1.1.C-12/1 / KONV-2012-0014. project. ISBN 978-963-473-831-2. pp. 1-205.

Kowalska, A. (2018): The study of the intersection between food fraud/adulteration and authenticity, Acta Universitatis Agriculturae et Silviculturae Mendelianae Brunensis, 2018. 66. 5. pp. 1275-1286.

https://doi.org/10.11118/actaun201866051275 
Lees, M. (2000): Food authenticity and traceability. Woodhead Publishing Limited. 1-585. eBook ISBN: 9781855737181. Hardcover ISBN: 9781855735262

Liu, J. (2016): Terahertz spectroscopy and chemometric tools for rapid identification of adulterated dairy product, Optical and Quantum Electronics, 2016. 49. 1.

https://doi.org/10.1007/s11082-016-0848-8

Mabood, F. - Abbas, G. - Jabeen, F. - Naureen, Z. - AlHarrasi, W. - Hamaed, A.M. - Hussain, J. - Al-Nabhani, M. - Al Shukaili, M.S. - Khan, A. - Manzoor, S. (2018): Robust new NIRS coupled with multivariate methods for the detection and quantification of tallow adulteration in clarified butter samples. Food Additives \& Contaminants: Part A. 2018. 35. 3. pp. 404-411.

https://doi.org/10.1080/19440049.2017.1418090

Mancini, G. - Carbonara, A. - Heremans, J. F. (1965): Immunochemical quantitation of antigens by single radial immunodiffusion. Immunochemistry, 1965. 2. pp. 235-254. https://doi.org/10.1016/0019-2791(65)90004-2

Monteiro, C.A. - Moubarac, J.C. - Cannon, G. - Ng, S.W. Popkin, B. (2013): Ultraprocessed product are becoming dominant in the global food system. Obesity Reviews. 2013. 14. 2. 21-28.

https://doi.org/10.1111/obr.12107

Moore, J.C. - Spink, J. - Lipp, M. Development and application of a database of food ingredient fraud and economically motivated adulteration from 1980 to 2010 . Journal of Food Science, 2012. 77. 4. pp. 118-126. https://doi.org/10.1111/j.1750-3841.2012.02657.x

Moreno, J. - Peinado, R. (2012): Enological chemistry. Elsevier. 1-429. eBook ISBN: 9780123884398

Hardcover ISBN: 9780123884381

Moyer, D.C. - DeVries, J.W. - Spink, J. The economics of a food fraud incident - Case studies and examples including Melamine in Wheat Gluten, Food Control, 2017. 71. pp. 358364.

https://doi.org/10.1016/j.foodcont.2016.07.015

Nedeljković, A. - Rösch, P. - Popp, J. - Miočinović, J. Radovanović, M. - Pudja, P. (2016): Raman spectroscopy as a rapid tool for quantitative analysis of butter adulterated with margarine. Food Analytical Methods. 9. 5. pp. 1315-1320. https://doi.org/10.1007/s12161-015-0317-1

Poonia, A. - Jha, A. - Sharma, R. - Singh, H.B. - Rai, A.K. - Sharma, N. (2016): Detection of adulteration in milk: A review, International Journal of Dairy Technology. 70. 1. pp. 23-42. https://doi.org/10.1111/1471-0307.12274

Reynolds, A.G. (2010): Managing wine quality. Volume 1. Viticulture and wine quality. Woodhead Publishing Limited. pp. 1-606. Hardcover ISBN: 9781845694845

eBook ISBN: 9781845699284
Ribani,A. - Schiavo, G. - Utzeri, V.J. - Bertolini, F. - Geraci, C. - Bovo, S. - Fontanesi, L. (2018): Application of next generation semiconductor based sequencing for species identification in dairy products. Food Chemistry, 2018. 246. pp. 90-98.

https://doi.org/10.1016/j.foodchem.2017.11.006

Rioux, S. Capitalist food production and the rise of legal adulteration: Regulating food standards in 19th century Britain. Journal of Agrarian Change. 2018. 19. 1. pp. 64-81. http://doi.org/10.1111/joac.12265

Singhal, R.S. - Kulkarni, P.R. - Rege, D.V. (1997): Handbook of indices of food quality and authenticity. Woodhead Publishing Limited. 1997. pp. 1-561.

eBook ISBN: 9781855736474

Spink, J. (2011): The challenge of intellectual property enforcement for agriculture technology transfers, additives, raw materials, and finished goods against product fraud and counterfeiters. Journal of Intellect Property Rights. 16. 2. pp. 183-193.

http://foodfraud.msu.edu/wp-content/uploads/2013/04/JIPR162-183-193.pdf

Spink, J. (2019): Food Fraud and adulteration: Where we stand today. Encyclopedia of Food Chemistry, 2019. 10. pp. 657-662.

Spink, J. - Hegarty, P.V. - Fortin, N.D. - Elliott, C.T. Moyer, D. C. (2019): The application of public policy theory to the emerging food fraud risk: Next steps. Trends in Food Science \& Technology, 2019. 10.1.

https://doi.org/10.1016/j.tifs.2019.01.002

Spink, J. - Ortega, D.L. - Chen, C. - Wu, F. (2017): Food fraud prevention shifts the food risk focus to vulnerability, Trends in Food Science \& Technology, 2017. 62. 215-220. https://doi.org/10.1016/j.tifs.2017.02.012

Sun, D.V. (2008): Modern techniques for food authentication. Elsevier. 2008. pp. 1-714.

Wartha V. (1880): On the counterfeiting of red wines. In Hungarian. Published reprint in Hungarian Chemist's Journal 2011. 66. 364. and The World of Nature 117:1:1986 http://chemonet.hu/hun/teazo/erjedes/warthav.html

Wilson, B. (2008): Swindled. The dark history of food fraud, from poisoned candy to counterfeit coffee. Princeton University Press. 2008. pp. 1-364. ISBN: 9780691138206

Wolfschoon-Pombo, A.F. - Furtado, M.A.: Detection of adulteration of pasteurised milk with whey by determination of the casein-bound phosphorus and protein nitrogen content. Zeitschrift für Lebensmittel-Untersuchung und Forschung. 1989. 1. pp. 16-21. 
Wu, Y. - Miao, H. - Shao, B. - Zhang, J. - Spink, J W. Moyer, D.C. Food Fraud, Food Safety in China, 253-270. In: Eds. Jen, J.J. - Chen, J. Food safety in China: Science, technology, management and regulation. John Wiley \& Sons. 2017.

https://doi.org/10.1002/9781119238102.ch16

Yang, X. - Jia, Z. - Tan, Z. - Xu, H. - Luo, N. - Liao, X. (2016): Determination of melamine in infant formulas by fluorescence quenching based on the functionalized $\mathrm{Au}$ nanoclusters. Food Control. 2016. 70. pp. 286-292.

Yang, Y. - Huisman, W. - Hettinga, K.A. - Liu, N. - Heck, J. - Schrijver, G.H. - Gaiardoni, L. - van Ruth, S.M. Fraud vulnerability in the Dutch milk supply chain: Assessments of farmers, processors and retailers, Food Control, 2019. 95. pp. 308-317.

https://doi.org/10.1016/j.foodcont.2018.08.019

(C) 2019 by the authors. This article is an open access article distributed under the terms and conditions of the Creative Commons Attribution (CC BY) license (http://creativecommons.org/licenses/by/4.0/). 